\title{
Research on the Internal Report System Based on Management Accounting
}

\author{
Yanjie Ma, Xiaoxian Gong \\ Dongfang College, Shandong University of Finance and Economics, Tai’an, Shandong, 271000
}

Keywords: Management Accounting, Internal Report System, Enterprise Financial System

\begin{abstract}
In the course of China's comprehensive promotion of economic construction and increasing level of economic globalization, the pressure of competition for enterprises has been gradually increasing. However, the problems facing the enterprises in development should not be overlooked. In order to better meet the needs of business management activities and promote the sustainable development of enterprises, enterprises must proceed from reality, effectively integrate the modern management of enterprises and information technology, and gradually establish a sound management accounting based internal reporting system to enhance the level of internal management of enterprises for the internal management activities to provide an effective basis for the guidance.
\end{abstract}

\section{Introduction}

Accounting is an ancient discipline whose origins can be traced back to the various types of books in the pockets of merchants on the Mediterranean coast about 500 years ago. Practice has proved an invariant law, that "the more economic development, the more important the accounting." In the face of rapid changes and fierce market competition, modern enterprises have fully entered a strategic orientation of the management era, pay more attention to the internal management Decision-making management, so the exploration of the internal management mode, the selection of internal management methods has become one of the goals pursued by modern enterprises. The carrier of all this is the demand for information. The current financial and accounting reports focus on reflecting business activities of enterprises after the event information, mainly for investors, creditors, the public and other external stakeholders use and business responsible for the management of the insiders in order to complete the organization set goals so that enterprises Forever the competitive advantage Naturally, information has its own unique needs. However, the current external accounting report system is difficult to satisfy, so it is very important to develop and regulate the internal accounting report system.

\section{Research Significance of Internal Reporting System Based on Management Accounting}

The construction of internal reporting system needs to be based on management accounting, so as to ensure that the strategic management and optimal allocation of resources can be smoothly realized. The construction of internal management accounting report system is of great significance in several aspects. First, the construction of internal reporting system based on management accounting can largely reform and perfect the accounting report system, and change the existing system of reporting based solely on external reports Model for business management and development to provide a more comprehensive and accurate information resources to reduce the internal and external uncontrollable factors on the impact of business development. Second, the internal report of the enterprise is the key component of establishing and perfecting the internal control system. The internal report system based on the management accounting as the guideline constructs effectively satisfies the requirement of perfecting and developing the internal system of the enterprise, so that the internal control system is more complete, Also better meet the business needs of the management accounting information. Third, the enterprises are facing more and more competitive pressures, so the managers of the enterprises must accurately forecast and make decisions on the current development of the enterprises. If they rely solely on the traditional 
financial accounting reports to manage their operations, Investment and financial development to predict, then, can not meet the needs of the actual business development, but also affect the individual development of enterprises. Therefore, the establishment of an internal reporting system based on management accounting can improve the internal management of enterprises and promote the efficient operation of enterprises. Fourthly, the internal report of management accounting plays an important role in optimizing the allocation and effective integration of enterprise resources, and also provides impetus for the integration and sharing of resources. Fifth, the internal report of the management accounting can provide guarantee for the operation and development of the enterprise after it is constructed, raise the enthusiasm of all functional departments and staffs in an all-round way, and create greater economic and social benefits.

\section{Design Principles and Ideas of Internal Report}

As a source of information for the modern enterprise to maintain a competitive position, internal reporting functions to integrate the internal information of an enterprise. Specifically, internal reports need to accurately and promptly reflect the operation status of enterprises to internal decision-makers, provide favorable information support for internal management decision-making of enterprises, and satisfy the information requirements of evaluating the operating performance of the relevant responsible centers and responsible persons and implementing incentives. In order to better play the role of internal reports, I believe that in the design of internal reports, we should follow the following principles [1].

Internal reporting to play the role of management accounting forecasting, decision-making, planning, control and evaluation, one of the most important issues is to consider the relevance of information. In other words, the information provided in internal reports should help policy makers understand the impact of different options on the future financial position. Therefore, the information must be timely, appropriate and appropriate. Due to the different purposes of using information, there are different ways of information processing, such as cost-reflecting information, historical cost, standard cost, fixed cost, variable cost, incremental cost, marginal cost, opportunity cost and so on. When preparing internal reports, different cost information needs to be selected. For example, standard costs and incremental costs should be considered in internal reports of forecasting decisions. Historical costs should be taken into account in internal planning control reports. Different objectives and requirements, determine the scope of the costs are also different, the processing methods are also inevitable differences. Therefore, considering the relevance of information is an important part of the preparation of internal reports. In addition, in terms of the sources of information, internal reporting should focus on both information originating from within the organization as well as information external to the organization [2].

Internal reports are not formally bound or limited by specific guidelines or norms, so the internal reports are diversified in form. As long as the information provided is relevant to the decision, all that can reveal the substance of an economic phenomenon can be adopted by internal reporting. For example, internal reports can be prepared in various forms such as text forms, graphic forms, digital forms, integrated forms, oral forms and media forms. Regardless of the form of internal reporting, it can be widely used if it is helpful for future decision-making, providing more comprehensive information for the managers of the enterprises and meeting the usefulness of decision-making.

One of the objectives of internal reporting is control, and its preparation should be made before significant changes occur in the results of the production and operation and before the effective intervention by the regulatory authorities. However, the length of time depends on the key economic activities that are measured. That is, internal reports can be prepared on a regular and non-periodic basis. When there is a significant change in the operating performance indicators, such as an unusually high rejection rate, or an unexpected major incident, an emergency report should be promptly submitted. The report is in fact prepared in real time, that is, in relation to the time when the incident occurred Basic synchronization, to attract the attention of managers and timely intervention. For important and ever-changing issues such as new orders, new customers, changes in cash flows, etc., they can be compiled on a daily basis. The evaluation of the responsible center 
can be made on a regular basis, such as monthly and quarterly. In addition, the responsible units that are closer to the grassroots level should report more frequently, and the purpose is to enable superiors to find out the problems in time [3].

\section{Foundation of Internal Reporting System}

Modern management accounting theory that the focus of management in business, business focus in the decision-making. While decision-making is future-oriented, good forecasting is the basis for decision-making and the prerequisite for scientific decision-making and the guarantee for the feasibility of decision-making. The management forecast in management accounting precisely predicts and measures the future development trend and situation of production and business activities according to the inherent relations between the existing economic conditions and the historical data and objective things of the enterprise according to certain principles and procedures. Prediction analysis is not a budget analysis, but the premise and basis of decision-making. It is an important basis for providing scientific judgment for business decision-making. Through the forecast, we can scientifically determine the product mix, the best stock structure, etc. in order to reasonably arrange and use the existing manpower, material and financial resources and fully coordinate the business activities of the entire enterprise. The analysis of decision-making in management accounting emphasizes that the future management strategies, objectives, guidelines, measures and methods made by the managers at all levels are aimed at the problems facing the future business activities of the enterprise, taking full account of various possibilities. Decision-making process [4]. Decision analysis usually runs through the whole process of production and business activities, so there are many criteria for the classification. The most commonly used management accounting selected in this paper is classified according to the length of the decision-making period, which is divided into short-term management decision and long-term management decision.

Short-term forecasting decision-making Internal report is mainly for the immediate benefit, refers to the year can achieve the decision-making, that is, in the short term how to maximize profit, so in building the internal report should be related costs, unrelated costs, the relevant business volume Key Analysis Objectives Long-term forecasting decisions Internal reports tend to be those decisions that are relatively expensive and long payback times to achieve. In addition to maximizing profits, social goals such as legal and ethical decisions influences. Therefore, in the construction of internal reports should be the time value of money, the value of investment risk, cost of capital and cash flow as the main analysis of the target. In general, the decision-making report should be based on the time-value, cost, profit and other factors and cost allocation as the basis for the report. In management accounting, planning and control accounting plays a role in connecting. It is a comprehensive budget process to implement the established decision-making plan, with the objective of decision-making and operating principles already defined. Therefore, the content of the internal reporting system in the planning and control phase should be based on the contents of the overall budget. That is, on the one hand, it reflects the specific information related to the decision-making plan and on the other hand, it should reflect the control program information that ensures the expected production and management objectives are achieved [5].

The overall budget of an enterprise for producing and operating a business over a certain period is a quantitative description of the total plan and it is a collection of relevant budgets. With the development and improvement of management accounting, the composition of the comprehensive budget system is gradually expanding. This article still adopts the traditional overall budget system as the basis for building the internal reporting system in the planning control stage. That is, the overall budget should include the business budget and the financial budget. The so-called financial budget mainly refers to the budget, which directly relates to the daily activities of supply, production and sales, including the sales budget, production budget, direct materials and procurement budget, direct labor budget, manufacturing cost budget, product cost budget, ending inventory budget, sales and Management expense budget. Business budget with physical indicators and value indicators reflect the composition of corporate income and expenses. The financial budget 
refers to the budgets that reflect the cash receipts and expenditures, operating results and financial status of the enterprise during the budget period. Mainly include cash budget, estimated income statement and estimated balance sheet. The financial budget reflects the results of the operating budget and capital expenditure budget in terms of value indicators.

According to the division of responsibility center, the internal reporting system of responsibility accounting can be divided into internal reports of cost centers, internal reports of profit centers and internal reports of investment centers. So as to reflect the budget implementation of each responsibility center and evaluate the managers. Because cost centers bear the responsibility of controlling costs, internal reporting of cost centers should reflect the performance of budgets for decomposing controllable costs. The internal reports of cost centers can be compiled based on the actual cost and the budget of the responsible costs and the necessary explanations of the differences between the two. Since the profit center is responsible for the cost and is responsible for the revenue and profit, the internal report of the profit center should make comparative analysis on the cost, the budgetary budget and the actual number of income, and check the completion of many indicators such as cost, profit and income and promptly Identify the problem and take the necessary steps to correct the deviation. The internal report of profit center fully reflects the difference and rate of difference between the budget of responsibility and actual implementation of income, cost and profit. Since investment centers are not only responsible for costs, revenues and profits but also for their investment results, the investment center's internal reports should include, in addition to the budget, revenue, and profit budgets, actual numbers, differences, and variance rates, List the sales profit rate, asset turnover rate, return on investment and residual rate of return of the budget, the actual number of differences and differences in rate, and its evaluation.

\section{Conclusions}

The construction of internal reporting system based on management accounting is the need of enterprise strategy development as well as an important guarantee to improve the internal management system and ensure the stable operation of the enterprise. Therefore, the managers of enterprises must improve their emphasis on the construction of the internal reporting system of management accounting, and realize that the system can provide important information for the promotion of enterprise management and scientific decision-making and strictly follow the guidelines for the construction of internal reporting system, From the actual needs of enterprises to improve internal management accounting reports, promote the sustainable development of enterprises.

\section{References}

[1] Fang Dachun, Sun Mingyue. Strategic Orientation and Path Selection of the Construction of the Yangtze River Economic Belt [J]. Journal of Hubei University of Economics, 2014 (12): 5 - 7.

[2] Liu Wei. Analysis of regional economic disparity in the Yangtze River economic belt [J]. Resources and Environment in the Yangtze Basin, 2006 (3): 33 - 35

[3] Chen Xiuying. Evolution and reorganization of the spatial structure of the Yangtze River economic belt [J]. Journal of Geographical Science, 2007 (12): 9 - 13.

[4] Peng Jinsong. Adjustment of Yangtze River Economic Belt Industrial Structure and Distribution [J]. Shanghai Economic Research, 2005 (4): 44 - 46.

[5] Li Xuegong. Spatial Distribution of Modern Port Logistics Industry [J]. Water Transport Management, 2007 (29): 22 - 24. 